\title{
Co-precipitation of silica and alkaline-earth carbonates using TEOS as silica source
}

\author{
Alina E. Voinescu ${ }^{\mathrm{a}}$, Matthias Kellermeier ${ }^{\mathrm{a}}$, Anna M. Carnerup ${ }^{\mathrm{b}}$, Ann-Kristin Larsson ${ }^{\mathrm{b}}$,

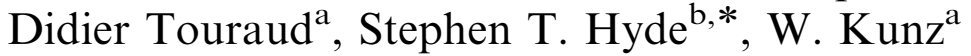 \\ ${ }^{a}$ Institute of Physical and Theoretical Chemistry, University of Regensburg, D-93040, Germany \\ ${ }^{\mathrm{b}}$ Department of Applied Mathematics, Research School of Physical Sciences, Australian National University, Canberra ACT 0200, Australia
}

Received 7 December 2006; received in revised form 17 February 2007; accepted 6 March 2007

Communicated by K. Sato

Available online 21 April 2007

\begin{abstract}
We explore the use of tetraethoxysilane (TEOS) as a silica source for the formation of carbonate-silica composite materials known as 'biomorphs'. The basic hydrolysis of TEOS furnishes silica in a controllable fashion, allowing a significantly higher reproducibility of the obtained silica-barium and silica-strontium carbonate co-precipitates compared to commercial water glass silica used so far. We further discuss the influence of ethanol used as a co-solvent on the morphologies of biomorphs, which are examined by optical microscopy, field emission scanning electron microscopy (FESEM) and energy dispersive X-ray analysis (EDX).
\end{abstract}

(C) 2007 Elsevier B.V. All rights reserved.

PACS: 81.10.Dn; 81.16.Dn

Keywords: A2. Growth from solutions; B1. Barium carbonate composite; B1. Biomorphs; B1. Organic silica; B1. Strontium carbonate composite

\section{Introduction}

Silica-carbonate "biomorphs" are characterised by a wide range of non-crystallographic, biomimetic morphologies. For example, micron-sized worm-like biomorphs [1] mimic closely the chemical composition and morphologies of oldest microfossils [2].

The formation of these crystalline aggregates (biomorphs) involves two simultaneous, likely coupled processes $[3,4]$ : the nucleation and growth of alkaline-earth carbonate crystals, and polymerisation of silicate species into silica. The resulting aggregates display striking structural features at many length scales, reminiscent of natural biominerals [5]. They are built in part of rodshaped nano-crystallites of the alkaline-earth carbonate, typically $200 \mathrm{~nm}$ in length, that adopt the usual aragonite crystal structure, evidenced by X-ray diffraction. These rods are organised to form orientational ordering of the

\footnotetext{
${ }^{*}$ Corresponding author.

E-mail address: stephen.hyde@anu.edu.au (S.T. Hyde).
}

crystal axes, with a slight twist between adjacent crystallites, giving characteristic radial textures in transmission optical microscopy between crossed polarisers. The rods are embedded in an amorphous silica matrix, giving a nano-scale composite. The radial ordering imparts striking micrometre-scale morphologies to the biomorphs, discussed below.

Until now, biomorphs have been grown with water glass as the silicate source [6]. Commercial water glass solution contains $29.7 \mathrm{wt} \% \mathrm{SiO}_{2}$, though its detailed chemistry is inherently complex, comprised of an undefined mixture of different silicate species and $14 \mathrm{wt} \% \mathrm{NaOH}$. Its alkaline character induces $\mathrm{CO}_{2}$ dissolution which lowers the $\mathrm{pH}$. In addition, aging of silica glass is likely to change the silica speciation in solution, due to the complex kinetics of silica oligomerisation. The age of water glass solutions can therefore significantly affect the experiments. Indeed, in some cases, we have observed that a specific water glass batch fails to form biomorphs despite its efficacy in earlier experiments. In those cases, a new batch of water glass (as supplied) has induced biomorph formation. 
Since the $\mathrm{pH}$ of the growth solution and the concentration of silica species during precipitation are critical factors in the resulting morphologies of biomorphs, we are investigating other silica sources whose characteristics can be better controlled, in order to obtain firmer data linking material morphology to the chemical species and environment. To this end, we have studied the efficacy of tetraalkoxysilanes $\mathrm{Si}(\mathrm{OR})_{4}$ [7] as a silica source, due to its defined starting composition and $\mathrm{pH}$ stability under storage. These organic silanes produce silica solutions in situ by hydrolysis. We have used tetraethylorthosilicate (TEOS) as a precursor. Tetrapropylorthosilicate (TPOS) and tetrabutylorthosilicate (TBOS) were also considered, but they are not soluble even upon addition of a co-solvent. There is extensive literature on the hydrolysis of TEOS in aqueous solutions [8,9], and the subsequent silica polymerisation. Acidic or basic catalysis is commonly used to induce and control this process. As biomorphs form at $\mathrm{pH}$ values around 10.5, TEOS hydrolysis was done under basic conditions (formed by addition of $\mathrm{NaOH}$ ). Since TEOS and $\mathrm{H}_{2} \mathrm{O}$ are immiscible, the reaction was carried out with ethanol (EtOH) as a co-solubiliser for TEOS, though the addition of EtOH adds an extra dimension to the complexity of the silicate solution. We show here that TEOS can be effectively used as a silica source, allowing better chemical characterisation and tunability of the system compared with the water glass precursors. We also investigate the influence of $\mathrm{EtOH}$ on the self-assembly process of biomorphs to shed light on the complex issue of silica chemistry and its influence on biomorph formation.

The mechanism for the basic hydrolysis of TEOS was first proposed by Iler [10]. This follows a nucleophilic $\mathrm{SN}_{2}-$ type reaction in which $\mathrm{OH}^{-}$displaces the $-\mathrm{OR}$ rests. Under most conditions, condensation commences before hydrolysis is complete. However, adequate choice of parameters like $\mathrm{pH}[11,12]$, time and $\mathrm{H}_{2} \mathrm{O} / \mathrm{Si}$ molar ratio can force completion of the hydrolysis before condensation starts [13]. According to Coradin et al., silicon alkoxides allow a better control of the reaction kinetics than otherwise possible [14].

\section{Experimental procedure}

\subsection{Materials preparation}

TEOS (purity $>98 \%$ ), barium chloride dihydrate (purity $>99 \%$ ), strontium chloride dihydrate (purity 99\%) and sodium hydroxide $(\mathrm{NaOH}$, purity $99 \%)$ were purchased from Sigma-Aldrich and used without further purification. EtOH was purified by distillation before use. Purified water with an electrical conductivity of less than $10^{-6} \mathrm{~S} \mathrm{~m}^{-1}$ was taken from a Milli-Q system.

The alkaline silica solution was prepared in a $100 \mathrm{ml}$ plastic beaker by mixing TEOS (7.5 or $8.9 \mathrm{mM})$, EtOH, $\mathrm{NaOH}$ and water in appropriate molar ratios and stirred for $60 \mathrm{~min}$ at ambient temperature. The EtOH content and the $\mathrm{pH}$ were varied from 0 to $10 \mathrm{vol} \%$ and from 9.5 to 12 , respectively. The biomorphs were grown by adding $0.5 \mathrm{ml}$ of a $1 \mathrm{M}$ barium chloride dehydrate or strontium chloride dehydrate. The resulting mixture was transferred to open reaction cells (plastic circular wells (Linbro Tissue Culture from INC Biomedical Inc.) $1.6 \mathrm{~cm}$ in diameter and $1.7 \mathrm{~cm}$ in depth) and left in contact to ambient atmosphere $\left(\sim 20^{\circ} \mathrm{C}\right)$. The barium biomorphs were grown in silica solutions for about 9-10 h. Alternatively, strontium biomorphs were grown in silica solutions for 5 and $15 \mathrm{~h}$. The diffusion of atmospheric $\mathrm{CO}_{2}(\sim 330 \mathrm{ppm}$ [15]) leads to the precipitation of self-assembled silica-barium or silicastrontium carbonates. The precipitates were washed several times with water and EtOH and examined by optical microscopy, then $\mathrm{Au} / \mathrm{Pd}$ coated for scanning electron microscopy. The $\mathrm{pH}$ was measured before and after growth.

\subsection{Analytical methods}

Light microscopy was performed using a stereo reflection microscope from Leica (Model MZ 12). Pictures were taken with a digital camera (Nikon, Coolpix 5000) having a resolution of 5.24 megapixels and zooms of $4 \mathrm{x}$ digital or $3 \mathrm{x}$ optical.

Field-emission scanning electron microscopy (FESEM) was performed using a microscope (Hitachi, Model S4500) operated at $3 \mathrm{kV}$. It has "upper and lower" secondary electron detectors (Robinson, Model Mk 6). The samples were coated in $\mathrm{Au} / \mathrm{Pd}$ with an Emitech sputter coater using a rotational stage.

The $\mathrm{pH}$ of the aqueous solutions was measured using an $\mathrm{Ag} / \mathrm{AgCl}$ plastic-body electrode (TPS, Model smartCHEM-Lab).

Energy dispersive X-ray (EDX) analysis was performed using an EDX microanalyser mounted on a Jeol JSM 6400 scanning electron microscope.

Dynamic Light Scattering (DLS) measurements were done using a Zetasizer spectrometer (Malvern Instruments, Model Z3000) equipped with a $633 \mathrm{~nm}$ Helium-Neon laser. Measurements were carried out exclusively at a scattering angle of $90^{\circ}$.

\section{Results and discussion}

\subsection{Influence of the EtOH concentration on the basic hydrolysis of $\mathrm{Si}\left(\mathrm{OC}_{2} \mathrm{H}_{5}\right)_{4}$}

The influence of $\mathrm{EtOH}$ on the basic hydrolysis of tetraethoxysilane was studied by varying its concentration whilst keeping the TEOS concentration constant at $7.5 \mathrm{mM}$ and $\mathrm{pH}$ 11. The hydrolysis reaction can be written as follows [16]:

$$
\mathrm{Si}(\mathrm{OEt})_{4}+2 \mathrm{H}_{2} \mathrm{O}+2 \mathrm{OH}^{-} \underset{\mathrm{EtOH}}{\rightleftharpoons} \mathrm{H}_{2} \mathrm{SiO}_{4}^{2-}+4 \mathrm{EtOH} \text {. }
$$

EtOH is both solvent and product of the hydrolysis reaction. In dilute solutions most of the monomers 
dimerise to form $\mathrm{Si}_{2} \mathrm{O}_{3}(\mathrm{OH})_{4}^{2-}$ [17]:

$$
\mathrm{SiO}(\mathrm{OH})_{3}^{-}+\mathrm{HO}-\mathrm{SiO}(\mathrm{OH})_{2}^{-} \rightleftharpoons \mathrm{Si}_{2} \mathrm{O}_{3}(\mathrm{OH})_{4}^{2-}+\mathrm{H}_{2} \mathrm{O} .
$$

Fig. 1 shows the change of the $\mathrm{pH}$ with time during TEOS hydrolysis at two different EtOH concentrations. At low EtOH content the curve exhibits two distinct parts. First, the $\mathrm{pH}$ decreases linearly as a function of time with a slope of $\alpha=-5.7 \times 10^{-4} \mathrm{~s}^{-1}$. Finally, the $\mathrm{pH}$ becomes nearly constant. The initial decrease in $\mathrm{pH}$ is due to the $\mathrm{SN}_{2}$ substitution. As soon as equilibrium is reached, the $\mathrm{pH}$ remains constant.

At high EtOH content, the curve can also be divided in two parts. In the early stage of the reaction, the $\mathrm{pH}$ again decreases linearly, but with a slope of $\alpha=-2.6 \times 10^{-3} \mathrm{~s}^{-1}$. After about $500 \mathrm{~s}$, however, the $\mathrm{pH}$ increases again. The positive slope in this part of the curve decreases towards zero at longer reaction times. Apparently, equilibrium is not completely reached after $1 \mathrm{~h}$.

The difference of the slopes in the early stage of the reaction can be explained by the different solubilisation rates of TEOS in the two media. At low EtOH content, TEOS is not fully solubilised at the beginning of the reaction and it takes a certain time for both the solubility and the equilibrium to be achieved. The subsequent $\mathrm{pH}$ increase during the later stage of the reaction at high $\mathrm{EtOH}$ content is consistent with initial formation of acidic silanol groups $(\mathrm{Si}-\mathrm{OH})$ during TEOS hydrolysis followed by their disappearance by condensation reactions $(\mathrm{Si}-\mathrm{O}-\mathrm{Si})$, proposed by Nagao et al. [18]. EtOH effectively enhances the propensity of the silica species to condense, via formation of relatively reactive $\mathrm{Si}-\mathrm{OH}$ species. The reaction medium is less polar, thus favouring the formation of polymeric silica.

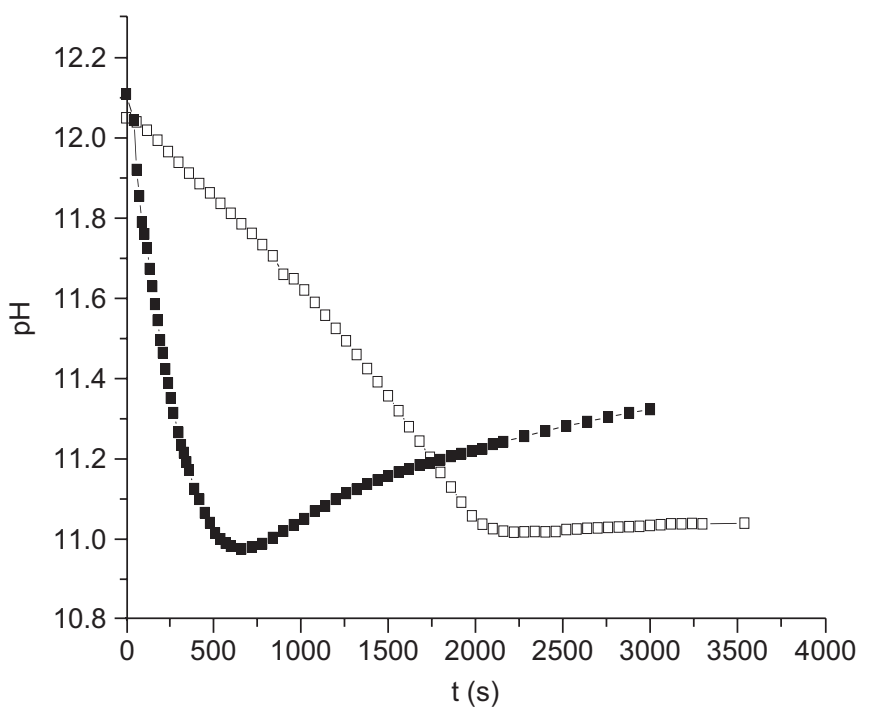

Fig. 1. $\mathrm{pH}$ variation with time in the reaction mixture during TEOS hydrolysis at $0.17 \mathrm{vol} \%(\square)$ and $10 \mathrm{vol} \%$ (口) EtOH.
As both the hydrolysis of TEOS and the subsequent polymerisation reactions are strongly dependent on time [19], the kinetics of silica formation can be varied in a controllable manner, allowing preparation of aqueous silicate solutions with reproducible species in solution. Therefore, TEOS affords a better defined source of silica than commercial water glass, improving the reproducibility of biomorph growth. Indeed, this fact could help us to better understand the mechanism of biomorph formation.

\subsection{Influence of EtOH on structure formation of biomorphs}

\subsubsection{Nucleation and initial growth}

Barium chloride was added immediately after TEOS hydrolysis was complete, as detected by $\mathrm{pH}$ measurements, discussed in the previous section. The growth of biomorphs was then followed by DLS from solutions with different EtOH content. The results are shown in Fig. 2. In the presence of metal cations, silica species nucleate and grow [19]. Addition of the barium salt to hydrolysed TEOS solutions containing $0.17 \mathrm{vol} \% \mathrm{EtOH}$ led to the formation of detectable nucleates after an incubation time of $10 \mathrm{~min}$ or more. The onset of nucleation $(r=105 \mathrm{~nm})$ was followed by a slow and gradual growth of the aggregates with time. Apparently, $\mathrm{Ba}^{2+}$ interacts with the negatively charged silicate species, thereby screening the surface charge of the anionic silica particles, leading to their aggregation.

In the alkaline TEOS solution rich in EtOH (10 vol\%), the addition of barium cations dramatically enhanced the nucleation, giving a cloudy appearance to the reaction mixture within a few minutes. After $1 \mathrm{~h}$, the resulting precipitate was collected and studied by means of SEM and EDX analysis. SEM images (Fig. 3(A)) show an amorphous-looking material consisting of $\mathrm{Si}$ and traces of Ba (EDX data). In a control experiment, in which no silica was present, well-defined micron-sized rod-like crystals

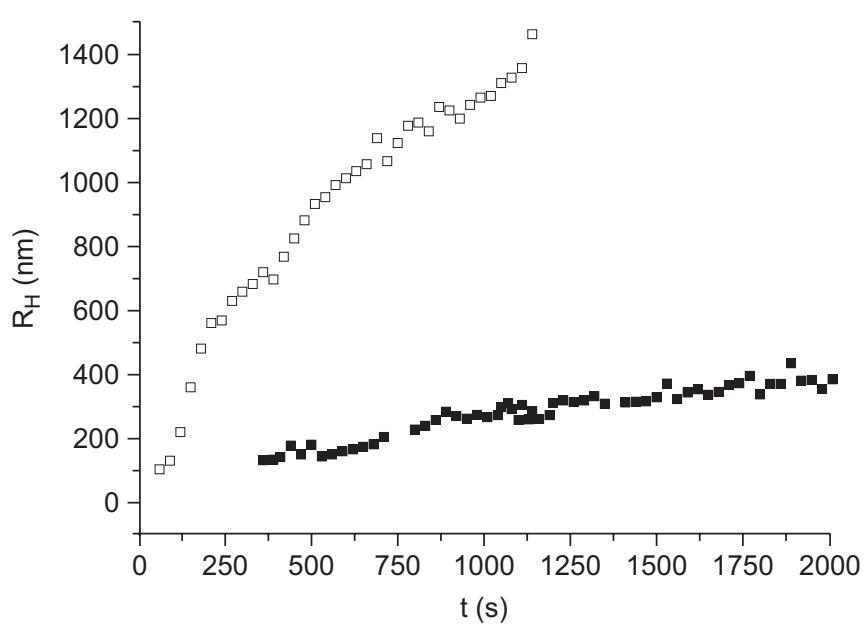

Fig. 2. Comparison of the light scattering curves obtained after rapidly mixing solutions of $\mathrm{BaCl}_{2}$ and TEOS hydrolysed at $0.17 \mathrm{vol} \%$ ( $\left.\mathbf{\square}\right)$ and 10 vol\% ( $\square$ ) EtOH. 
characteristic of witherite were produced within the same timeframe (Fig. 3(B)).

\subsubsection{Biomorphs characterisation after $9 \mathrm{~h}$ in contact with atmospheric $\mathrm{CO}_{2}$}

After a period of time comparable with that of water glass experiments [20], self-assembled silica-carbonate aggregates were formed. Fig. 4 shows optical micrographs of biomorphs at different $\mathrm{EtOH}$ concentrations and $\mathrm{pH} \sim 11$ (corresponding to the optimal $\mathrm{pH}$ at which the non-crystallographic helical filaments are found when conventional water glass is used). At low EtOH content, the resulting carbonate-silica biomorphs give similar morphologies to those produced using water glass as silica precursors. The helical filaments grow to a similar length $(100-200 \mu \mathrm{m})$ as found in 'standard' biomorphs. On raising
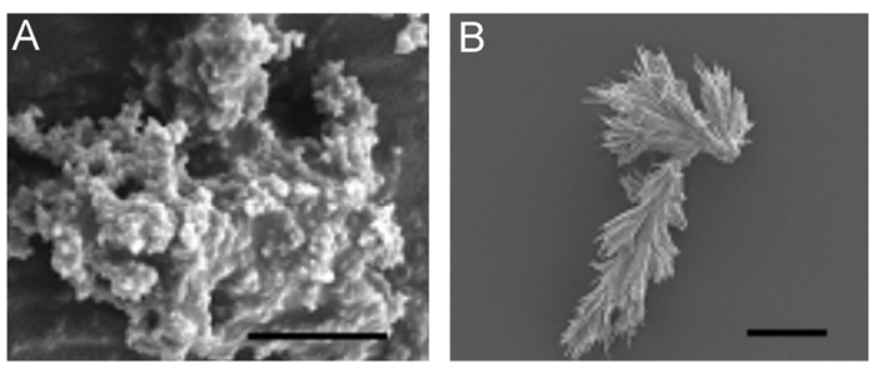

Fig. 3. SEM images obtained in the presence (A) and absence (B) of TEOS after $1 \mathrm{~h}$ from mixing solutions of $\mathrm{BaCl}_{2}$ and TEOS hydrolysed. Scale bar: (A) 1.5 and (B) $10 \mu \mathrm{m}$. the EtOH content, two, three or more helical filaments ramify from one nucleation point, a feature also observed in earlier work.

At $10 \mathrm{vol} \% \mathrm{EtOH}$, globular aggregates with apparently inter-grown filaments are observed. The size and shape of these globular clusters varies between 100 and $150 \mu \mathrm{m}$ (Fig. 5). The surface texture of the aggregates consists of orientationally ordered witherite nanorods. We could not find evidence of a surrounding silica skin, in contrast to the helical filaments grown from TEOS solutions with low EtOH content and already reported in water glass syntheses [1]. Another important observation concerns the nuclei distribution. Increased EtOH content leads to faster formation of a smaller number of particles.

Although the EtOH content ensures high miscibility of silanol groups $(\mathrm{Si}-\mathrm{OH})$ with water, the formation of typical biomorphs only occurs at low EtOH content. On the one hand, higher EtOH content strongly favours nucleation and the growth of silica after combining the silica sol and metal solutions. Possibly, EtOH molecules interact with the silica surface via $\mathrm{H}$-bonds and shield interactions with metal ions, at least to some extent [21]. More likely, the silica species interact with the EtOH molecules, forming reactive intermediates that subsequently condense to form silica oligomers. Consequently, the silica particles aggregate to form a concentrated colloidal phase. The light scattering data supports the hypothesis that silica is removed from the solution via condensation. This allows us to correlate the observed changes in morphology with uncondensed silica species in the reaction mixture [22].
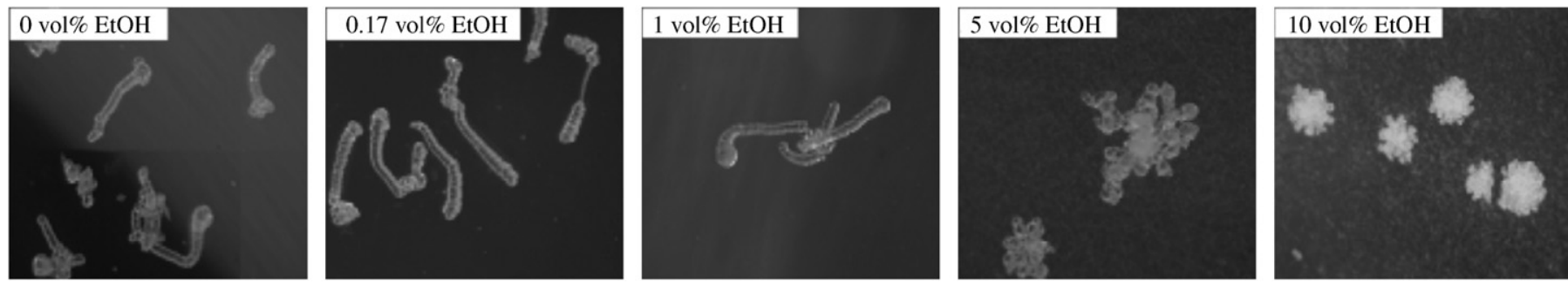

Fig. 4. Optical micrographs of self-assembled silica-carbonate at different $\mathrm{EtOH}$ vol $\%$. $[\mathrm{TEOS}]=7.5 \mathrm{mM},\left[\mathrm{Ba}^{2+}\right]=5 \mathrm{mM}, \mathrm{pH}=11, T=20^{\circ} \mathrm{C}$, and $t=9 \mathrm{~h}$.
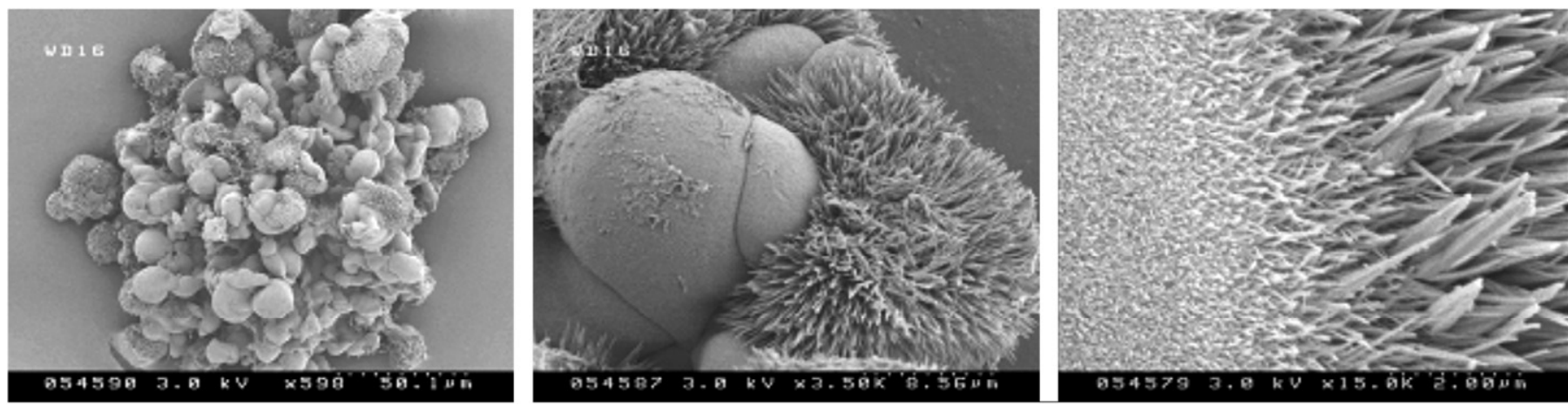

Fig. 5. Zoom sequence of globular aggregates, showing details of the surface texture. 


\subsection{Effect of $\mathrm{pH}$ on the formation of silica-carbonate biomorphs}

In the preceding section, it was shown that most biomorphs (helical filaments and worms) - hitherto grown in water glass - also appear in TEOS solutions at low
EtOH content. Fig. 6 gives FESEM images of silicabarium carbonate biomorphs grown in hydrolysed TEOS solutions containing $0.17 \mathrm{vol} \% \mathrm{EtOH}$ and $5 \mathrm{mM}$ barium chloride at various starting $\mathrm{pH}$ values. The given $\mathrm{pH}$ values correspond to the hydrolysed TEOS solutions after $60 \mathrm{~min}$ of mixing. The morphologies of the precipitates depend
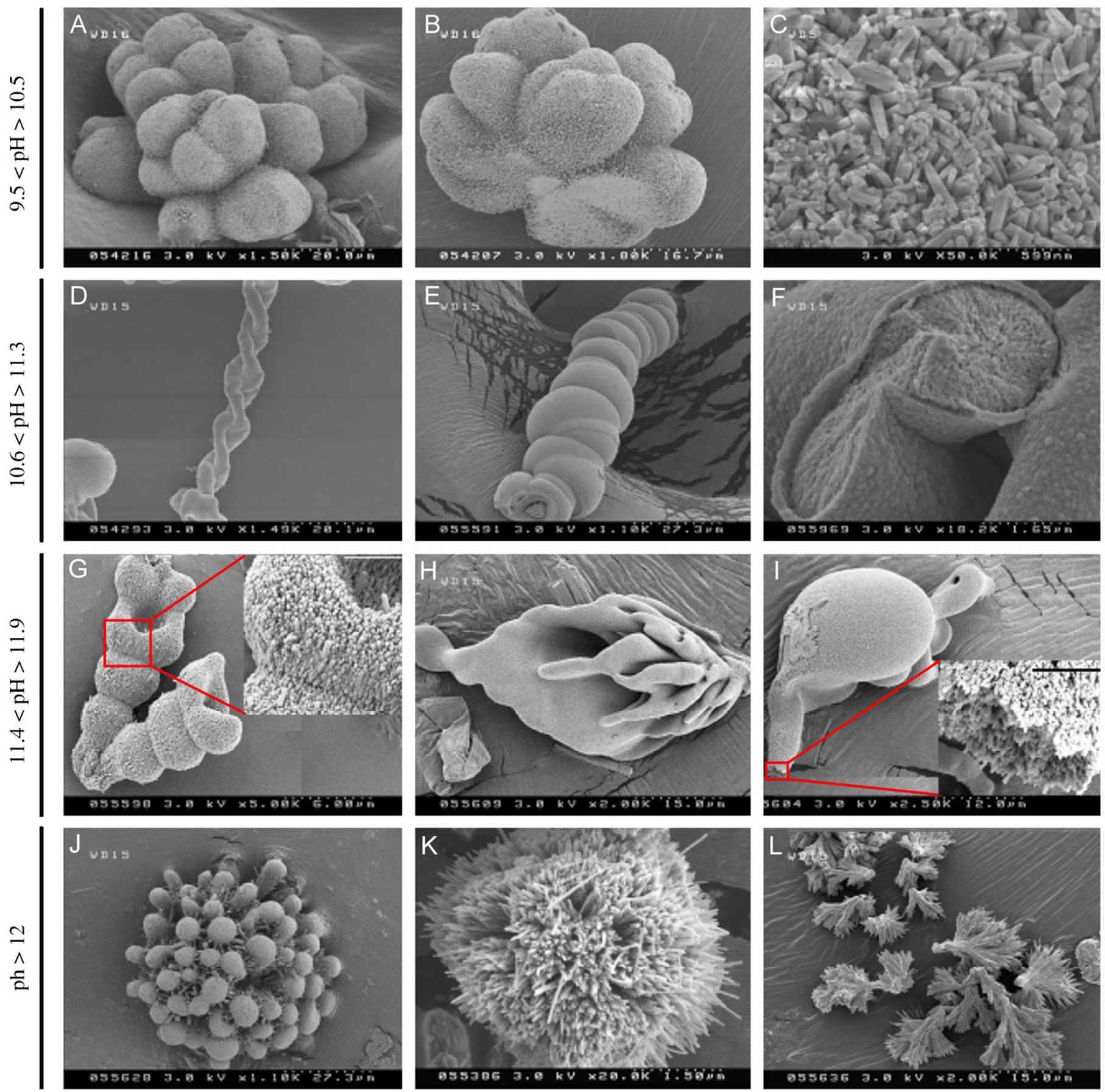

Fig. 6. FESEM images of a selection of various aggregates grown at $\mathrm{pH}$ values between 9.5 and 12. $[\mathrm{TEOS}]=7.5 \mathrm{mM},\left[\mathrm{Ba}^{2+}\right]=5 \mathrm{mM}, 0.17 \mathrm{vol} \% \mathrm{EtOH}$, $t=9 \mathrm{~h}$, and $T=20^{\circ} \mathrm{C}$. (A) - (C) Zoom sequence of 'cauliflower' biomorphs, showing details of the surface structure. (D) and (E) Helical barium carbonate biomorphs grown at $\mathrm{pH}=10.6-11.3$. (F) Silica skin, coating the exterior of the helical aggregates. (G)-(I) Non-crystallographic morphologies of BaCO ${ }_{3}$, showing the orientational ordering of crystallites (insets). (J) Colony-like aggregates of several globules arising from a single crystal core. (K) 'Hairy' spheres clusters with strong architectural resemblance to fluoroapatite-gelatin aggregates. (L) Micron-sized rod-like barium carbonate. Inset scale bar: (G) 1.2 and (I) $857 \mathrm{~nm}$. 
critically on the $\mathrm{pH}$ of the system. We observe $\mathrm{pH}-$ morphology relations for TEOS-induced biomorphs consistent with the progression seen in water glass experiments [5].

Uniform aggregates showing cauliflower-like morphologies, of about $75 \mu \mathrm{m}$ in length were produced by decreasing the $\mathrm{pH}$ from 10.5 to 9.7. The shape consists of several dendrite-like heads composed of radially aligned witherite $\left(\mathrm{BaCO}_{3}\right)$ crystals (see Figs. 6(A)-(C)). When the $\mathrm{pH}$ is decreased to below 9.5, no precipitation occurs.

Increasing the $\mathrm{pH}$ to 11 resulted in the formation of typical helical filaments of about $100-200 \mu \mathrm{m}$ in length and $5-15 \mu \mathrm{m}$ in width (see Figs. 6(D) $-(\mathrm{F})$ ). We have noted already the remarkable resemblance of these structures in size and shape to terrestrial bacteria and microfossils [23]. The filaments, 'twisted ribbons' (Fig. 6(D)) and 'worms' (Fig. 6(E)), are assemblies of micron-size witherite crystallites coated with a continuous silica matrix, identical to comparable biomorphs produced using water glass as silica source. EDX measurements were performed to determine the $\mathrm{Si}$ and $\mathrm{Ba}$ content (averaged over the silica membrane as well as the inside of the worm).

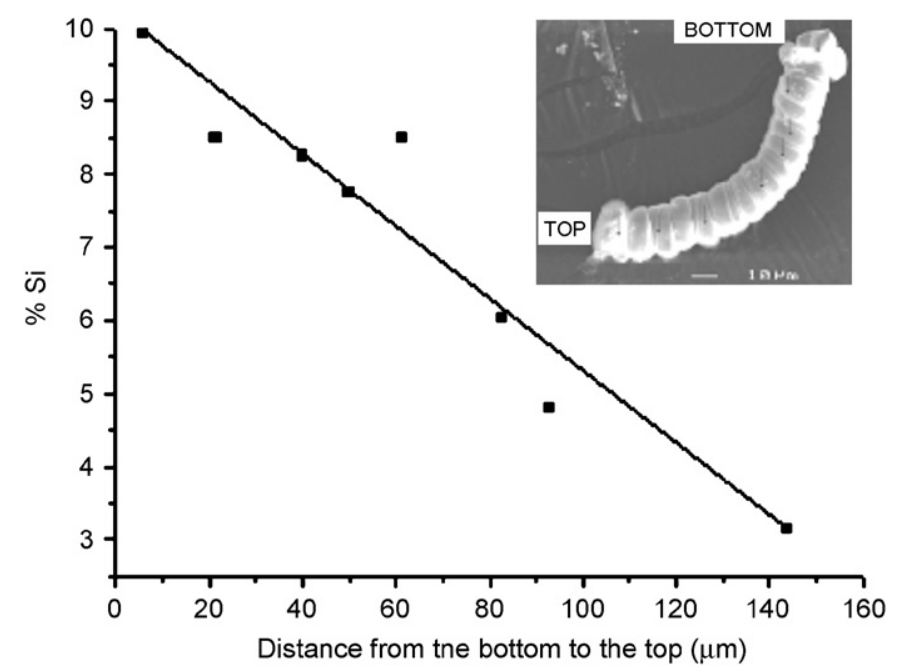

Fig. 7. Si content (relative to Ba) on the surface of a biomorph "worm" at different distances from the bottom of the worm.
Fig. 7 visualises the relative at $\%$ of $\mathrm{Si}$ (i.e. the fraction of $\mathrm{Si}$ atoms out of the total $\mathrm{Si}+\mathrm{Ba}$ atom count) on the surface of a biomorph worm at different distances from the bottom. It is evident that the relative $\mathrm{Si}$ content decreases smoothly from the starting point of growth to the later stages, when barium carbonate predominates.

Significant changes in the biomorph morphologies occur on increasing the $\mathrm{pH}$ further to 11.5 , where a wide range of novel, astonishing non-crystallographic morphologies such as 'snail'-like (Fig. 6(G)), 'arum-flower-like' (Fig. 6(H) and 'tortoise-like' (Fig. 6(I)) aggregates appear. Higher magnifications of the surface texture reveal that these biomimetic morphologies too are composed of arranged rods (see Fig. 6, insets) and lack a silica membrane. The helical filaments observed at $\mathrm{pH} 11$ are suppressed under these conditions.

Above $\mathrm{pH}$ 12, aggregates such as dendrite-shaped $\mathrm{BaCO}_{3}$ or 'hairy' spheres grow (Figs. 6(J) and (K)). These clusters are composed of radially aligned crystals. Similar shapes have been reported for other composite structures such as fluoroapatite-collagen aggregates [24]. Simultaneously, micron-sized particles consisting of witherite nanorods in parallel arrangement were generated in the reaction cells (Fig. 6(L)). The formation of these rods is not attributable to the presence of silicate anions since similar micron-scale morphologies were produced by diffusion of atmospheric $\mathrm{CO}_{2}$ into silica-free barium chloride solutions. Under these conditions, the dissolution of carbon dioxide is fast, silica condensation is minimal and therefore the silica exerts little influence on the morphology.

Lastly, we point out that the use of TEOS is not confined to growth of silica-barium carbonate biomorphs. Silicastrontium carbonate biomorphs also readily form under ambient conditions with TEOS as a silica source. The growth sequence of these strontium biomorphs mirrors exactly that of the strontium biomorphs grown using water-glass solutions as a silica source. Initially, floral spherulites were produced (Fig. 8(A)). The size of these globular clusters varies between 40 and $70 \mu \mathrm{m}$ and the thickness of the curvilinear sheets is about $2-4 \mu \mathrm{m}$.

If the cluster is left in solution for $15 \mathrm{~h}$, twisted filaments grow outward from the tips of these sheets (Fig. 8(B)). We note that the morphological evolution of the cluster grown
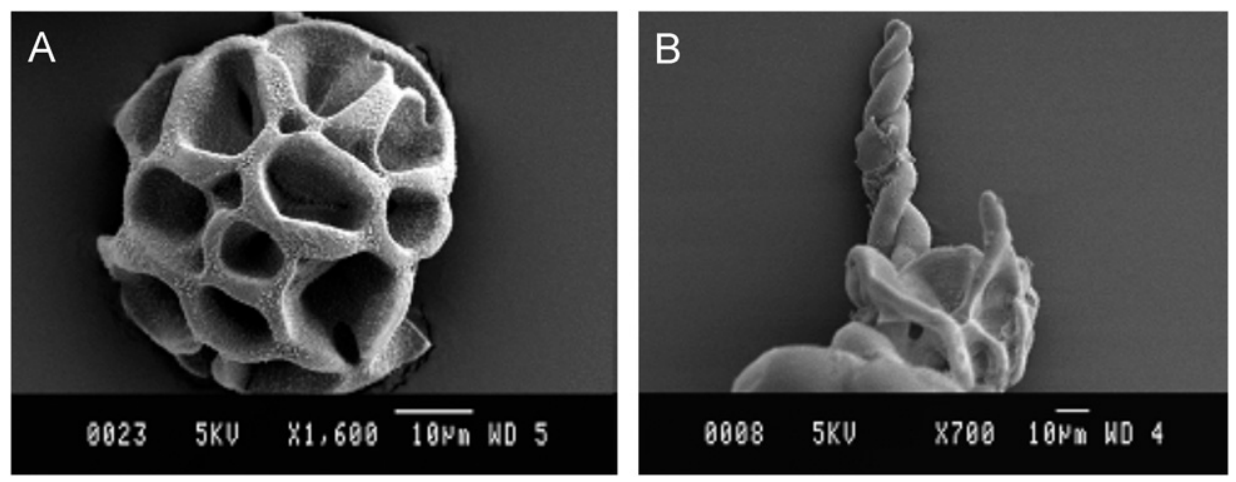

Fig. 8. SEM images silica-strontium carbonate biomorphs grown for 5 (A) and $15 \mathrm{~h}(\mathrm{~B})$ in TEOS solutions $(8.9 \mathrm{mM})$ at $\mathrm{pH} 11 \mathrm{containing} 5 \mathrm{mM} \mathrm{Sr}^{2+}$. 
in aqueous solution of TEOS bears a striking resemblance to that reported by Terada et al. [25]. In their case, strontium carbonate clusters were prepared in a silica gel at pH 10.5 .

\section{Conclusions}

Silica-carbonate biomorphs have been precipitated reproducibly using tetraethylorthosilicate (TEOS). Experiments were done in alkaline TEOS solutions at $\mathrm{pH}$ and concentrations identical to the former water glass experiments. It was found that TEOS offers an alternative silica source for the growth of biomorphs, provided the EtOH content remains low. Indeed, ethanol (EtOH), an essential co-solvent for TEOS solubilisation, has a significant effect on the growth process. Experiments conducted at high EtOH content led to fast formation of a small number of globular morphologies strikingly dissimilar to biomorphs. This is most likely due to the promotion of silica condensation in the presence of raised EtOH levels. It is therefore likely that the speciation of silica and the associated availability of silica to co-condense with the metal carbonate in the reaction mixture is a critical parameter for the formation of the complex curvilinear forms characteristic of biomorphs.

In conclusion, TEOS offers a preferred silica source over water glass solutions for detailed investigations of materialstructure aspects of these biomorphs, due to its better defined chemical properties. In summary, the use of TEOS in the presence of low concentrations of EtOH allows reproducible growth of biomorphs. We therefore recommend its use as a silica source for biomorph growth in place of water glass used previously. The control over kinetics and species of silica formation offered by hydrolysis of organic silanes (e.g. by variation of hydrolysis time) will allow us to tune the many parameters affecting biomorph formation more carefully, thereby improving our techniques for study of these fascinating materials.

\section{Acknowledgements}

The work was done during a 3-month stay of A.E. Voinescu in the Research School of Physical Sciences, Australian National University, Canberra. The authors are grateful to J.M. García-Ruiz for his comments and advice.

\section{References}

[1] J.M. Garcia-Ruiz, S.T. Hyde, A.M. Carnerup, A.G. Christy, M.J. Van Kranendonk, N.J. Welham, Science 302 (2003) 1194.

[2] J.P. Grotzinger, Early Life on Earth, University Press, New York, 1994 , p. 245

[3] J.M. Garcia-Ruiz, Bull. Mineral. 104 (1981) 107.

[4] J.M. Garcia-Ruiz, J. Crystal Growth 73 (1985) 251.

[5] J.M. Garcia-Ruiz, A.M. Carnerup, Ann-Kristin Larson, A.G. Christy, N.J. Welham, S.T. Hyde, Astrobiology 2 (2002) 353.

[6] S.T. Hyde, A.M. Carnerup, Ann-Kristin Larson, A.G. Christy, J.M. Garcia-Ruiz, Physica A 339 (2004) 24.

[7] C.J. Brinker, C.W. Scherer, Sol-Gel Science: The Physics and Chemistry of Sol-Gel Processing, Academic Press, London, 1990.

[8] J. Sefcik, A.V. McCormick, Catal. Today 35 (1997) 205.

[9] A. Boonstra, J.M. Baken, J. Non-Cryst. Solids 122 (1990) 171.

[10] R.K. Iler, The Chemistry of Silica, New York, 1979.

[11] S.L. Chen, P. Dong, G.H. Yang, J.J. Yang, Ind. Eng. Chem. Res. 35 (1996) 4487.

[12] E.R. Pohl, F.D. Osterholtz, Molecular Characterisation of Composite Interfaces, New York, 1985.

[13] S.H. Kim, B.Y.H. Liu, M.R. Zachariah, Langmuir 20 (2004) 2523.

[14] T. Coradin, P.J. Lopez, ChemBioChem 3 (2003) 1.

[15] A. Tomoda, Tokyo Ika Daigaku Zasshi 62 (2004) 641.

[16] S. Yang, A. Navrotsky, Chem. Mater. 16 (2004) 3682.

[17] S.A. Greenberg, D. Sinclair, J. Am. Chem. Soc. 9 (1955) 436.

[18] D. Nagao, H. Osuzu, A. Yamada, E. Mine, Y. Kobayashi, M. Konno, J. Colloid Interface Sci. 279 (2004) 143.

[19] G.T. Kerr, J. Phys. Chem. 70 (1966) 1047.

[20] J.M. Garcia-Ruiz, Orig. Life Evol. Biosph. 24 (1994) 451.

[21] G.W. Brindley, S. Ray, Am. Mineral. 49 (1964) 106.

[22] A. Larsson, A. Carnerup, S.T. Hyde, Morphology of helical, self assembled silica carbonate biomorphs, in preparation.

[23] J.W. Schopf, A.B. Kudryavtsev, D.G. Agresti, T.J. Wdowiak, A.D. Czaja, Nature 416 (2002) 73.

[24] R. Kniep, S. Busch, Angew. Chem. Int. 35 (1996) 2624.

[25] T. Terada, S. Yamaby, H. Imai, J. Crystal Growth 253 (2003) 435. 